\title{
Construção solidária do habitus escolar: resultados de uma investigação nos setores público e privado
}

\author{
ZAIA BRANDÃO \\ MARIA LUIZA CANEDO \\ ALICE XAVIER \\ Pontifícia Universidade Católica do Rio de Janeiro
}

Este trabalho desenvolve uma análise exploratória sobre a constituição de habitus escolares, baseada em parte do material empírico produzido por um survey aplicado a alunos, pais e professores em escolas públicas e privadas do Rio de Janeiro com os melhores desempenhos na Prova Brasil e ENEM. ${ }^{1}$ Os questionários foram desenvolvidos com o objetivo de obter subsídios para a compreensão da gestão institucional e familiar - do cotidiano dos estudantes em seus possíveis desdobramentos na constituição de habitus escolares. Questões sobre as práticas pedagógicas escolares, institucionais e familiares, o perfil dos alunos, das famílias e dos professores serviram para a construção de dados empíricos com os quais procuramos levantar algumas hipóteses sobre habitus que favorecem bons desempenhos escolares.

Embora tenhamos clareza da impossibilidade empírica de separar o que, no habitus dos estudantes, seria credor da escola ou da família, temos como objetivo

1 Foram utilizados os dados de 2005 a 2007 das avaliações oficiais de caráter nacional, sendo o Exame Nacional do Ensino Médio (ENEM) aplicado às escolas privadas e a Prova Brasil à rede pública. 
destacar aqueles valores, práticas e rotinas - enfatizados no cotidiano escolar de cada uma das instituições de nossa amostra - que repercutem no espaço familiar, e articulam-se aos valores, práticas e rotinas familiares na construção de disposições permanentes, favoráveis ao aprendizado escolar. No recorte do presente artigo, procuramos identificar estilos de gestão institucional e modelos pedagógicos que, em consonância com certos estilos familiares de lidar com a escolaridade dos filhos, repercutiriam na construção do habitus escolar. Apresentamos neste texto o resultado da reflexão sobre parte do material empírico produzido - observações de campo e questionários, explorando os dados das escolas públicas e privadas ${ }^{2}$ de nossa amostra que tratavam diretamente da construção do habitus escolar.

Ao destacar, sempre que possível, rotinas, valores, ênfases e controles aos quais os alunos são expostos no ambiente escolar e familiar, procuramos registrar as estratégias e ações que objetivam e provavelmente favorecem a criação de determinadas disposições (babitus) para o estudo e o domínio das habilidades necessárias ao bom desempenho escolar. As respostas dos alunos permitem inferir como estes se apropriam das estratégias colocadas em prática pelas famílias e escolas, enquanto agentes ativos, mediadores da construção solidária do habitus entre a família e a escola.

\section{A ENTRADA NAS ESCOLAS}

Desde os contatos telefônicos para apresentar os objetivos da pesquisa, até as primeiras visitas às escolas para negociar sua realização, as interações institucionais oferecem um rico material para a elaboração de um dossiê das escolas. O simples contato telefônico, para agendar a visita, permite uma primeira experiência que sugere estilos de gestão bastante distintos. Para algumas escolas a menção do nome da Instituição Universitária que abriga o nosso grupo de pesquisa era suficiente para o acesso ao campo. Em outras, esse acesso era fortemente filtrado por uma série de perguntas sobre por que e por quem o contato era reivindicado. E em algumas, ainda, uma espécie de protocolo padrão obrigava-nos a percorrer uma série de instâncias da hierarquia burocrático-institucional. Em um caso apenas (de um total

2 O subconjunto de escolas privadas (seis) é mais numeroso do que o das públicas (quatro) porque incluímos uma escola que já fizera parte do primeiro survey (objeto de pesquisa de um membro da equipe), e uma das escolas selecionadas para o survey solicitou a inclusão de outra unidade situada na Barra da Tijuca. 
de 11), nossa pretensão foi imediatamente negada ${ }^{3}$ por parte de uma escola que se enquadrava no perfil de empresa educacional ${ }^{4}$ (Paes de Carvalho, 2004).

Nesse período inicial, procuramos garantir uma agenda em aberto para nos ajustarmos aos horários que nos eram propostos pelas escolas. Na maioria das escolas, uma primeira visita era marcada em intervalos que não ultrapassaram um mês, após o primeiro contato. Duas foram as exceções:

- Uma escola privada na qual, depois de uma pré-negociação de quase dois meses, encontramos uma acolhida formal e uma escuta fria à explanação de nossos objetivos. Após uma semana, para nossa surpresa, fomos informados de que a instituição aprovara a pesquisa.

- Uma escola pública muito procurada por pesquisadores em razão de seu bom desempenho, mas na qual, em virtude de uma experiência relativamente recente e pouco positiva com a pesquisa de uma doutoranda (soubemos depois), a direção demonstrou inicialmente uma grande resistência em nos receber. Procuramos esclarecer as características de nosso trabalho, no qual o retorno do material produzido para debate com os agentes institucionais estava previsto, e enfatizamos a importância do registro da experiência pedagógico-administrativa ali desenvolvida, como subsídio para a melhoria do trabalho em outras escolas do sistema público municipal. A menção ao reconhecimento do valor dessa escola e a possibilidade de aproveitamento dessa experiência para a melhoria de outras escolas pareceu-nos ter funcionado como chave para quebrar a resistência inicial.

\section{CARACTERÍSTICAS TÍPICAS}

Compreender os processos de produção de qualidade de ensino, nos subsistemas privado e público do município, exige um cuidadoso registro dos recursos, características e condições de trabalho nos dois setores do ensino fundamental. As primeiras visitas da equipe às escolas já evidenciavam, dada a dispersão espacial das instituições no território municipal, os possíveis desdobramentos, sobre as condições de escolarização, as diferenças de acesso pelas populações locais aos setores de serviço público, tais como: saneamento, transporte, saúde, educação, lazer

3 Apesar de insistirmos, recorrendo à mediação de uma autoridade reconhecida nos meios educacionais, e com contato pessoal do diretor geral da instituição, fomos atendidos por um diretor de nível hierárquico inferior o qual, após várias protelações, nos recebeu atenciosamente, com a clara missão de nos fazer desistir de nossa demanda sem, entretanto, negá-la diretamente.

4 A caracterização de empresa educacional refere-se a escolas que têm sustentação econômica exclusivamente advinda das mensalidades pagas pelos alunos, vivenciando uma situação de grande dependência em relação às famílias dos alunos, que assumem a posição de consumidores do ensino. 
e bens culturais. Além disso, as próprias instalações das instituições selecionadas são fortemente distintas, expressando desigualdades tanto entre as redes quanto entre as diversas escolas de cada um dos sistemas educacionais investigados. As escolas privadas investigadas, que se mantêm nas primeiras posições no ENEM há vários anos, funcionam em prédios bem equipados e gozam de infraestrutura muito superior às das escolas pertencentes ao sistema municipal. As condições de trabalho nos dois sistemas são distintas, pois além dos salários das instituições privadas serem, em média, mais elevados do que os oferecidos pelo Município, a multiplicação das equipes didático-pedagógicas e o apoio logístico-administrativo das escolas privadas de nossa amostra tendem a oferecer condições de trabalho, aparentemente, mais adequadas ao nucleamento das preocupações das equipes pedagógicas em suas atividades-fim.

Cabe destacar que esses primeiros contatos com as equipes das escolas municipais nutriram o sentimento inicial de que os limites infraestruturais podem ser compensados por um estilo de direção multitarefa e um éthos institucional que contribuem para o desenvolvimento de um esprit de corps. Este parece desdobrar-se em resultados escolares muito superiores aos de outras escolas, com condições similares no que se refere ao campo pedagógico-administrativo.

Descrevemos, a título de ilustração, algumas das peculiaridades dos dois subsistemas derivadas das observações nas escolas e das conversas informais com as direções das escolas pesquisadas - no setor público e no privado. Cabe assinalar que o destaque dado às características típicas de cada subsistema de ensino deve ser compreendido na perspectiva dos tipos ideais weberianos. ${ }^{5}$

\section{No setor público - a presença da direção}

A escola municipal, que nos serve de base a esta ilustração, está situada em uma rua estreita e movimentada da zona suburbana, próxima a um bairro que reúne um dos maiores complexos de favela do município do Rio de Janeiro, a Maré. Ao chegarmos à escola, crianças pequenas - aparentemente da educação infantil -, sentadas junto a uma das paredes à entrada de um pátio coberto, aguardavam os responsáveis sob a vigilância de um funcionário. Um responsável pela limpeza ainda estava recolhendo seus equipamentos de trabalho. Ordem, cuidado e segurança discreta, em meio ao tumulto de uma região marcada pela violência, foram aspectos que se destacaram nas primeiras impressões. Fomos conduzidas com simpatia e presteza por um funcionário à sala da secretaria, indicando autonomia para identificar quem pode ter acesso à direção. Uma sala retangular repleta de mesas e com meia dúzia

5 Segundo Max Weber, Tipo Ideal é um modelo abstrato que nos permite observar aspectos do mundo real, estabelecendo padrões de comparação sem a preocupação de descrever uma situação específica. 
de funcionárias passa a sensação do burburinho de muitas atividades cruzadas. A diretora está entre as demais funcionárias, sem distinção hierárquica perceptível à primeira vista. Somos convidadas para nos acomodar no mesmo espaço, para onde foram deslocadas algumas cadeiras. Sobre seu tom de voz rouco, a diretora nos explica ser o resultado do seu estilo de falar muito e alto.

Nossa explanação sobre os objetivos da pesquisa e as razões da seleção daquela escola pela posição de destaque na Prova Brasil foi a deixa para que ela discorresse sobre as prioridades em torno do ensino, estilo da direção, perfil dos estudantes, famílias e corpo docente. De imediato assinalou que não utilizava a sala de direção, porque ficaria isolada e perderia a visão do movimento da escola. ${ }^{6}$ Fomos interrompidas algumas vezes pela entrada de professores e de alunos pequenos que traziam trabalhos artesanais, mostrando-os, um por um, à diretora, que demonstrava conhecê-los individualmente. A informalidade parece ser o tom padrão das relações na escola. Interagindo por cerca de uma hora com a diretora em meio a sua equipe, não restou dúvidas de onde emanava a autoridade. Esta parece ancorar-se numa presença constante da diretora - quase sempre das primeiras a chegar e a última a sair da escola - no "comando" do trabalho escolar, com o objetivo de manter o prestígio adquirido no sistema municipal. Dotada de um corpo docente estável, segundo ela, só permanecem na escola os professores que se comprometem com a qualidade da educação naquela instituição. Outro aspecto que chamou a atenção foi a demonstração de segurança em relação à sua autoridade, conferida por eleições sucessivas para o cargo. A escola é muito procurada e não consegue atender a todos: os alunos entram no $1^{\circ}$ ano e só saem ao final do ensino fundamental, "aqui não tem carteirada de políticos para furar a fila na hora da matrícula", afirmou a diretora, cuja centralidade na escola é inquestionável.

\section{No setor privado - a infraestrutura material}

No caso da escola privada, a direção, desde o primeiro encontro, nos atendeu acompanhada do coordenador pedagógico. A partir desse momento, todo o nosso trabalho passou a ser mediado pelas coordenações pedagógicas. No caso das escolas privadas de nossa amostra, diferentemente do que observamos nas municipais, as equipes pedagógicas contam com um suporte técnico, material e administrativo bastante amplo. A escola, unidade de uma instituição com sede situada na Zona Sul da cidade, tem menos de dez anos e está instalada no interior de um condomínio na Barra da Tijuca. O conjunto arquitetônico recém-construído distribui-se por uma ampla área. Duas barreiras antecediam a nossa entrada - a do condomínio e a da portaria da escola, onde nos anunciamos aos dois vigilantes, através das janelas

6 Um sistema de monitoramento utilizando um aparelho de televisão instalado no alto da sala permitia visualizar os diversos espaços escolares. 
envidraçadas em meio a um grande muro branco. Um espaço ajardinado, fruto de um bem elaborado projeto paisagístico, e um parquinho infantil, à esquerda de quem entra, acolhem os visitantes. À direita, uma passagem larga leva ao prédio principal, onde se situam os espaços de atividades didáticas. $\mathrm{O}$ complexo de prédios de dois a três pavimentos, que compõem as instalações da escola, espalha-se pelo terreno povoado de árvores, entre as quais frondosas figueiras e mangueiras sombreiam espaços de convívio e de recreação. Canteiros com flores e folhagens próximos a bancos de madeira ou cimento contornam áreas de circulação entre os prédios. A biblioteca, instalada no andar térreo de um dos prédios, é toda envidraçada, muito clara e com um bom acervo de livros na área infantojuvenil, como pudemos perceber ao percorrer o setor com mais vagar; o acesso aos livros é direto e mesas e pufes oferecem espaços confortáveis para os leitores. Em rápida conversa com a bibliotecária percebemos o entusiasmo de quem se sente responsável pela orientação das aquisições para o acervo.

Almoçamos no restaurante da escola, enquanto aguardávamos o coordenador pedagógico, ${ }^{7}$ que ficou diretamente responsável por nos fornecer o apoio necessário para o desenvolvimento do survey. Apesar do horário (quase duas da tarde) ainda havia alguns funcionários, professores e alunos mais velhos finalizando as refeições. Auditórios, laboratórios, pátios cobertos para recreação, cantinas e salas de aulas localizadas em espaços diferentes para os dois segmentos - ensino fundamental e ensino médio - interligam-se por corredores espaçosos e claros. Graças ao estilo arquitetônico e ao material de construção, os ambientes distribuem-se harmoniosamente em diferentes níveis, quebrando assim a rigidez dos andares superpostos. Simplicidade requintada seria a expressão adequada para descrever o sentimento ambíguo de conjugação de uma decoração despojada e dispendiosa, planejada em cada detalhe, e utilizando material de qualidade com o objetivo de proporcionar a sensação de conforto e funcionalidade.

Esse cenário abriga uma equipe pedagógico-administrativa na qual a figura do diretor perde centralidade - diferentemente do que assinalamos no caso da escola pública -, de tal forma que, muitos dos alunos do $9^{\circ}$ ano, ao responderem os questionários, demonstraram não saber quem era o diretor(a) da escola. Coordenações de vários tipos (de segmentos de ensino, pedagógicos, de disciplinas, de artes, de educação física, entre outros) articulam-se no trabalho de planejamento, desenvolvimento e controle das atividades. Os recursos materiais e logísticos estão presentes em uma proporção muito superior aos da maioria das escolas de ensino fundamental, seja no setor público ou privado.

Em que pesem essas impressões iniciais, ilustradas por esses dois casos, a análise preliminar dos dados do survey, que apresentamos a seguir, já nos permitiu revisitar os primeiros registros de campo, e esboçar outros cenários com base no

$\overline{7}$ O coordenador ocupava-se de um problema de última hora, antes de nos atender. 
cotejo público-privado. A continuidade das análises - com base no banco de dados da pesquisa e no detalhamento dos recortes - permitirá um conjunto de tomadas de cena do geral (conjunto das escolas, setores público e privado) ao específico (cada uma das unidades escolares ou subconjuntos que se mostrem pertinentes) na tentativa de construir cenários cada vez mais densos para a interpretação do material empírico.

\section{UM OLHAR A PARTIR DAS FAMÍLIAS}

A visão da sociologia da educação sobre as relações entre famílias e escolas tem se transformado. A nomeação no singular, família-escola, quando se tinha como referência o padrão da família nuclear heterossexual, ${ }^{8}$ vem sendo preterida por seu uso no plural, famílias-escolas, em virtude do reconhecimento de uma extensa gama de formações familiares, decorrentes de novas combinações de estruturas e valores (recasamentos, casais homossexuais, famílias monoparentais, uniões estáveis e tantas outras).

É antiga e indiscutível a imbricação das duas instituições na produção dos resultados escolares. Desde os famosos surveys dos anos 1960 e 1970 (INED/França, Coleman/EUA e Plowden/Inglaterra, entre outros), o reconhecimento das raízes sociais das desigualdades escolares levou os pesquisadores da educação a focalizarem o protagonismo das famílias nos processos de escolarização. Entre eles, dois autores merecem destaque pela importância de suas pesquisas, para a compreensão e interpretação do impacto da socialização familiar na construção do sucesso ou fracasso escolar: Basil Bernstein e Pierre Bourdieu.

A identificação da centralidade da experiência linguística sobre as trajetórias escolares foi um achado importantíssimo para a investigação das relações entre as famílias e as escolas. Com base na teoria dos dois códigos - elaborado e restrito-, utilizados respectivamente pelas camadas médias/superiores e pelas camadas populares, Bernstein (apud Forquin, 1995, p. 116) caracterizou uma oposição linguística e sociologicamente pertinente para a interpretação das desigualdades sociais de escolarização.

No caso de Bourdieu (1979), o habitus - disposições sociais duradouras, incorporadas desde a infância sob a influência familiar/social, que permitem ao agente reproduzir os padrões de ação (perceptivos, motores, conceituais, verbais) próprios de seu grupo ou classe social ${ }^{9}$ - foi um conceito fundamental para a

8 Família nuclear no modelo típico da modernização/urbanização em que espaços domésticos reduzidos correspondem a células compostas de casal e filhos ou família ampliada, incluindo parentes e agregados tais como tios, primos e outros.

9 Razôes práticas que dispensam escolhas racionais ao operarem adequadamente em resposta às exigências do campo em que atuam - linguístico, escolar etc. 
compreensão dos processos de reprodução das desigualdades sociais em todos os campos do espaço social. ${ }^{10}$

No Brasil, Paulo Freire (1989) foi sem dúvida o autor que, para além do diagnóstico das fortes imbricações entre linguagem/cultura e classes sociais, demonstrou um caminho para a superação do abismo entre a escolarização e as diferenças culturais de socialização e de condições de vida. A pesquisa e a utilização na alfabetização de adultos das palavras-chave - carregadas de significado cultural e ancoradas na experiência cotidiana dos aprendizes - permitiram provar o caráter social, e não individual, das dificuldades de aprendizagem entre as classes populares.

A questão do sucesso e fracasso escolar, portanto desde as décadas de 1960 e 1970, e especialmente fundamentada nos aportes derivados das investigações empíricas do campo da sociologia da educação, afastou-se decisivamente da suposição de que os principais responsáveis pelo bom ou mau desempenho seriam os dons e aptidões individuais. Ao mesmo tempo, o reconhecimento da importância da família na construção do habitus - onde se incluem as disposições linguísticas e culturais - marcou fortemente o rumo das investigações sobre sucesso e fracasso escolar, e deve hoje, necessariamente, passar pela análise das articulações, implícitas ou explícitas, tensas ou cooperativas, entre famílias e escolas.

\section{Características das famílias investigadas}

Apesar das diferenças socioculturais das famílias dos alunos investigados, nas escolas públicas e particulares, as representações e ações de ambos os grupos sugerem uma verdadeira parceria ${ }^{11}$ das famílias com as escolas no processo de escolarização dos estudantes.

As tabelas que se seguem delineiam o perfil sociocultural das famílias investigadas, com base nas informações obtidas com os questionários, para uma melhor compreensão das diferenças de status sociocultural entre elas. Essa caracterização é importante para a compreensão das relações entre famílias e escolas na construção do sucesso escolar. Entretanto, o próprio material empírico que produzimos nos permite perceber que o sucesso e o fracasso não podem ser interpretados como derivados mecanicamente dos perfis familiares. ${ }^{12}$

10 Expressão utilizada pelo autor para se referir à sociedade como composta por um conjunto de espaços relativamente autônomos - os campos sociais.

11 Ver C. Paes de Carvalho e P. Lacerda (2007) para melhor compreensão.

12 A suposição de uma relação quase automática entre o nível sociocultural das famílias e o sucesso ou fracasso escolar dos filhos levou a que se cristalizassem preconceitos que penalizaram, e ainda penalizam, muitos estudantes dos setores populares. Desde o final da década de 1990 pesquisas na área da sociologia da educação têm analisado 
Quadro 1 - Responsável pelo aluno

\begin{tabular}{|l|r|r|}
\hline \multicolumn{1}{|c|}{ Qual é a sua relação de parentesco com o aluno? } & Rede Privada & Rede Pública \\
\hline Pai & $21 \%$ & $17 \%$ \\
\hline Mãe & $78 \%$ & $77 \%$ \\
\hline Outra & $1 \%$ & $6 \%$ \\
\hline
\end{tabular}

Fonte: Elaboração das autoras.

Quadro 2 - Estado civil do responsável

\begin{tabular}{|l|r|r|}
\hline \multicolumn{1}{|c|}{ Qual é o seu estado civil? } & Rede Privada & Rede Pública \\
\hline Solteiro & $5 \%$ & $28 \%$ \\
\hline Casado & $71 \%$ & $52 \%$ \\
\hline Divorciado ou separado & $19 \%$ & $11 \%$ \\
\hline Viúvo e outros & $5 \%$ & $9 \%$ \\
\hline
\end{tabular}

Fonte: Elaboração das autoras.

Conforme esperado, observamos no Quadro 1 que tanto entre os alunos da rede pública quanto da privada é a mãe quem ocupa, na grande maioria das famílias, a posição de responsável pelo acompanhamento escolar dos filhos.

No que se refere à autoindicação de estado civil, o casamento certamente não é mais a única forma de conjugalidade. Vale destacar que a indicação de "casado" aparece no Quadro 2 com muito maior frequência (71\%) entre as famílias de maior nível socioeconômico (nas escolas públicas $28 \%$ das mães apresentam-se como solteiras). Podemos levantar a hipótese de que entre as famílias populares, nas quais não há patrimônio ou linhagem a ser transmitida, as aspirações pela forma legitimada de união estejam menos presentes.

Já a perspectiva amplamente difundida de que as mães dos alunos da rede pública têm menos disponibilidade de tempo para se dedicar aos filhos parece encontrar pouco respaldo no universo investigado. No Quadro 3 verificamos que, enquanto o percentual de donas de casa é bem superior entre as famílias populares, o trabalho com dedicação integral aparece com maior frequência entre as famílias de melhores condições socioeconômicas.

a construção do sucesso escolar entre jovens de famílias dos setores populares, com baixa escolarização e renda. Ver Lahire (1997), no plano internacional, e Souza e Silva (2003), Braga Viana (2007) e Portes (1993), entre os autores brasileiros. 
Quadro 3 - Situação de trabalho do responsável

\begin{tabular}{|l|r|r|}
\hline \multicolumn{1}{|c|}{ Qual é sua situação de trabalho } & Rede Privada & Rede Pública \\
\hline Aposentado, pensionista ou incapacitado & $3 \%$ & $6 \%$ \\
\hline Estudante & $2 \%$ & $1 \%$ \\
\hline Desempregado (procurando emprego) & $2 \%$ & $8 \%$ \\
\hline Dona de casa & $8 \%$ & $28 \%$ \\
\hline Trabalha em tempo parcial & $18 \%$ & $16 \%$ \\
\hline Trabalha em tempo integral & $60 \%$ & $34 \%$ \\
\hline Estuda e trabalha & $7 \%$ & $7 \%$ \\
\hline
\end{tabular}

Fonte: Elaboração das autoras.

Quadro 4 - Escolaridade da mãe

\begin{tabular}{|l|r|r|}
\hline \multicolumn{1}{|c|}{ Até que série a mãe estudou? } & Rede Privada & Rede Pública \\
\hline Nunca estudou & - & $1 \%$ \\
\hline Ensino fundamental & $1 \%$ & $41 \%$ \\
\hline Ensino médio & $5 \%$ & $26 \%$ \\
\hline Ensino superior & $41 \%$ & $12 \%$ \\
\hline Pós-graduação & $42 \%$ & $4 \%$ \\
\hline Não sabe informar & $11 \%$ & $16 \%$ \\
\hline
\end{tabular}

Fonte: Elaboração das autoras.

\section{Quadro 5 - Escolaridade do pai}

\begin{tabular}{|l|r|r|}
\hline \multicolumn{1}{|c|}{ Até que série o pai estudou? } & Rede Privada & Rede Pública \\
\hline Nunca estudou & - & $1 \%$ \\
\hline Ensino fundamental & $1 \%$ & $32 \%$ \\
\hline Ensino médio & $6 \%$ & $26 \%$ \\
\hline Ensino superior & $37 \%$ & $11 \%$ \\
\hline Pós-graduação & $43 \%$ & $3 \%$ \\
\hline Não sabe informar & $13 \%$ & $27 \%$ \\
\hline
\end{tabular}

Fonte: Elaboração das autoras.

Como se pode observar nos Quadros 4 e 5, os perfis das famílias usuárias das escolas públicas e privadas praticamente se invertem no que concerne à escolarização dos pais. Enquanto $83 \%$ das mães e $80 \%$ dos pais dos alunos das escolas privadas têm nível superior, e destes $42 \%$ e $43 \%$ respectivamente têm pós-graduação, entre os pais de alunos das escolas públicas apenas 16\% das mães e 14\% dos pais alcançaram esses patamares de escolarização.

No que se refere ao capital cultural ${ }^{13}$ das famílias, que pode ser disponibilizado para apoio a escolarização dos filhos, procuramos investigar a posse de livros e o

13 Bourdieu observa que o capital cultural é o conjunto de qualificações/disposições intelectuais adquiridas no ambiente familiar, no meio social e no sistema escolar ele pode existir de forma incorporada (um "ter" tornado "ser", propriedade feita corpo), materializada como posse de bens culturais (livros, obras de arte) e institucionalizada, ou seja, socialmente sancionado por instituições (títulos escolares, prêmios). 
acesso digital. Constatamos que, conforme detalhado no Quadro 6, enquanto 73\% das famílias das escolas públicas indicam ter em casa menos de 20 livros, $84 \%$ das famílias da rede privada dizem contar com mais de 20 ou mais de 100 exemplares.

Também a posse de computadores e o acesso à internet, indicados nos Quadros 7 e 8 , revelam diferenças marcantes em favor das famílias das escolas privadas, uma vez que $26 \%$ das famílias da rede pública ainda não dispõem de computadores em casa enquanto $43 \%$ das famílias na rede privada possuem três ou mais equipamentos.

Quadro 6 - Posse de livros

\begin{tabular}{|l|r|r|}
\hline \multicolumn{1}{|c|}{ Quantos livros há em sua casa? } & Rede Privada & Rede Pública \\
\hline Nenhum & $1 \%$ & $16 \%$ \\
\hline O bastante para encher uma prateleira (1 a 20) & $15 \%$ & $57 \%$ \\
\hline O bastante para encher uma estante (20 a 100) & $41 \%$ & $21 \%$ \\
\hline O bastante para encher várias estantes (mais de 100) & $43 \%$ & $6 \%$ \\
\hline
\end{tabular}

Fonte: Elaboração das autoras.

Quadro 7 - Acesso à internet

\begin{tabular}{|l|r|r|}
\hline \multicolumn{1}{|c|}{ Acesso à Internet } & Rede Privada & Rede Pública \\
\hline Não tem & $1 \%$ & $36 \%$ \\
\hline Um ponto & $36 \%$ & $58 \%$ \\
\hline Dois pontos ou mais & $63 \%$ & $6 \%$ \\
\hline
\end{tabular}

Fonte: Elaboração das autoras.

Quadro 8 - Posse de computadores

\begin{tabular}{|l|r|r|}
\hline \multicolumn{1}{|c|}{ Posse de computador } & \multicolumn{1}{|c|}{$\begin{array}{c}\text { Rede } \\
\text { Privada }\end{array}$} & Rede Pública \\
\hline Não tem & - & $26 \%$ \\
\hline Um & $22 \%$ & $64 \%$ \\
\hline Dois & $35 \%$ & $8 \%$ \\
\hline Três ou mais & $43 \%$ & $2 \%$ \\
\hline
\end{tabular}

Fonte: Elaboração das autoras.

A distribuição da renda mensal das famílias das escolas privadas e públicas correspondente à soma dos salários de ambos os pais, como aparece no Quadro 9 - reproduz o mesmo fenômeno de inversão observado em relação à escolarização dos pais. Apenas um dos pais dos alunos das escolas privadas declarou renda mensal de até $\mathrm{R} \$ 930,00,{ }^{14}$ enquanto essa é a situação de 216 (entre 467) pais dos alunos das escolas públicas investigadas. No caso de renda mensal acima de $\mathrm{R} \$ 4.650,00$,

14 As faixas de renda utilizadas foram definidas em função de múltiplos do salário mínimo nacional vigente na ocasião da construção dos questionários. 
apenas 11 indicações foram encontradas entre os pais da rede pública, ao passo que nas escolas da rede privada 498 pais (entre 578) declararam renda mensal acima desse valor, como indicam as curvas de renda familiar no Gráfico 1.

\section{Quadro 9 - Distribuição percentual da renda familiar}

\begin{tabular}{|c|c|c|c|c|c|}
\hline \multicolumn{3}{|c|}{ Renda familiar mensal - escolas privadas } & \multicolumn{3}{|c|}{ Renda familiar mensal - escolas públicas } \\
\hline Renda familiar mensal & Freq. & $\%$ & Renda familiar mensal & Freq. & $\%$ \\
\hline Até $\mathrm{R} \$ 930,00$ & 1 & 0,2 & Até $\mathrm{R} \$ 930,00$ & 216 & 46,3 \\
\hline De $R \$ 931,00$ a $R \$ 1.860,00$ & 7 & 1,2 & De $\mathrm{R} \$ 931,00$ a $\mathrm{R} \$ 1.860,00$ & 129 & 27,6 \\
\hline De $R \$ 1.861,00$ a $R \$ 4.650,00$ & 53 & 9,2 & De $R \$ 1.861,00$ a $R \$ 4.650,00$ & 77 & 16,5 \\
\hline De $R \$ 4.651,00$ a $R \$ 9.300,00$ & 144 & 24,9 & De $R \$ 4.651,00$ a $R \$ 9.300,00$ & 9 & 1,9 \\
\hline De $R \$ 9.301,00$ a $R \$ 13.485,00$ & 103 & 17,8 & De R\$9.301,00 a R\$13.485,00 & 2 & 0,4 \\
\hline Acima de $\mathrm{R} \$ 13.485,00$ & 251 & 43,4 & Acima de $\mathrm{R} \$ 13.485,00$ & 0 & 0,0 \\
\hline Não respondentes & 19 & 3,3 & Não respondentes & 34 & 7,3 \\
\hline Total & 578 & $100 \%$ & Total & 578 & $100 \%$ \\
\hline \multicolumn{3}{|l|}{ Acima de $\mathrm{R} \$ 4.651,00-86,1 \%$} & \multicolumn{3}{|l|}{ Acima de $\mathrm{R} \$ 4651,00$ - 86,1\% } \\
\hline
\end{tabular}

Fonte: Elaboração das autoras.

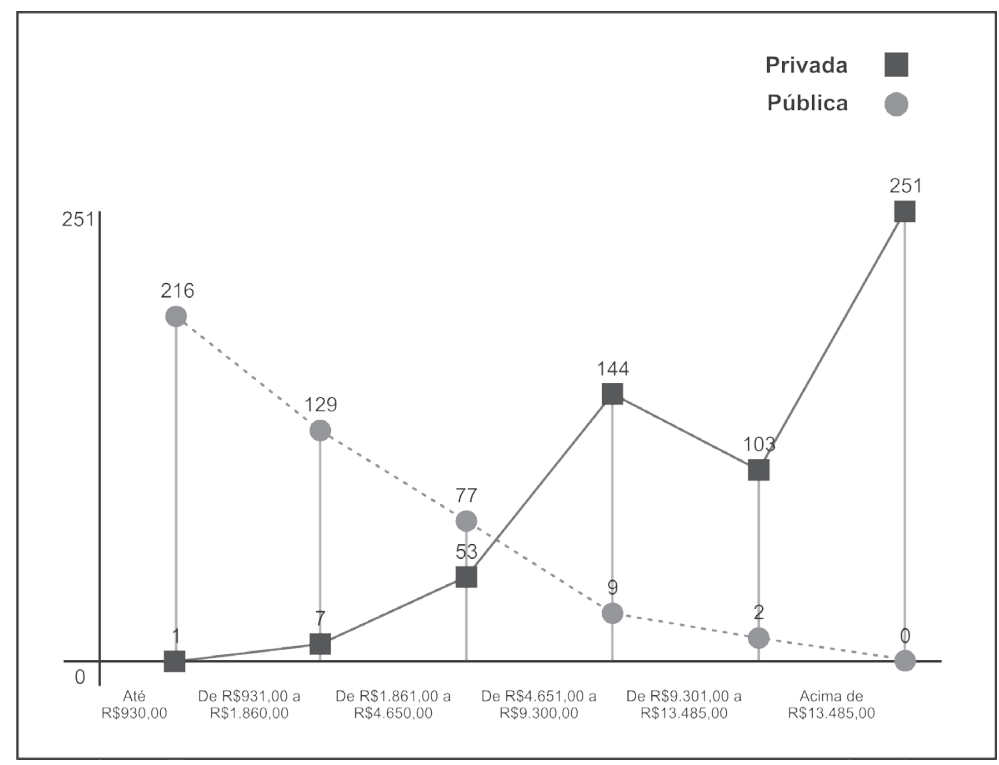

Figura 1 - Gráfico: Curvas de renda familiar por rede

Fonte: Elaboração das autoras.

Esses perfis socioeconômicos familiares tão díspares, no que se referem às condições de escolarização e renda das gerações mais velhas, não pareceram, no entanto, desdobrar-se em dificuldades insuperáveis para o acompanhamento e suporte da escolaridade das novas gerações, como procuraremos indicar com base no material empírico. 


\section{As expectativas em relação às escolas}

A escolha da escola significa um primeiro movimento familiar na construção da trajetória escolar dos filhos. Nossa pesquisa ${ }^{15}$ abrange famílias com maior ou menor grau de autonomia para essa escolha, ou seja, famílias que podem arcar com os custos de escolas privadas de prestígio - normalmente com mensalidades próximas ou superiores a $\mathrm{R} \$ 1.000,00$-, e outras com menor renda, cujas opções se restringem ao setor público, pela impossibilidade de arcar com as mensalidades escolares dos filhos. Mesmo dentro de limites de ordem financeira, nossos dados indicam expectativas elevadas nos dois subgrupos a respeito das escolas, conforme é possível inferir a partir dos motivos de escolha da escola ${ }^{16}$ dos filhos indicados pelas respostas aos questionários que aparecem no Quadro 10a.

Quadro 10a - Motivos de escolha da escola

\begin{tabular}{|l|r|r|}
\hline \multicolumn{1}{|c|}{ Motivo de escolha da escola } & $\begin{array}{c}\text { Rede } \\
\text { Privada }\end{array}$ & Rede Pública \\
\hline A escola oferece ensino de boa qualidade & $98 \%$ & $93 \%$ \\
\hline A escola exige disciplina e bom comportamento dos alunos & $87 \%$ & $95 \%$ \\
\hline Meu filho terá boas companhias & $81 \%$ & $78 \%$ \\
\hline A escola é aberta ao diálogo com os pais & $76 \%$ & $92 \%$ \\
\hline É uma escola bem falada & $75 \%$ & $89 \%$ \\
\hline
\end{tabular}

Fonte: Elaboração das autoras.

Comparando os aspectos que foram considerados pelos pais como muito importantes na escolha da escola, observamos que cinco motivos figuram com as mais fortes indicações em ambos os grupos, merecendo especial atenção:

- Oferta de ensino de boa qualidade aparece como importante critério entre as famílias de ambas as redes, $98 \%$ na rede privada e $93 \%$ na pública;

- Escola que exige disciplina e bom comportamento aparece com o mais alto percentual de indicações entre os pais da rede pública, 95\%, mas também com percentual significativo na rede privada, $87 \%$, indicando que a função disciplinadora da escola é ainda bastante valorizada principalmente pelas famílias populares;

- Convivência com boas companbias é indicada por $81 \%$ dos pais da rede privada e por $78 \%$ da rede pública, o que pode indicar para a valorização do capital social que começa a ser construído no âmbito da escola no ensino fundamental;

$15 \mathrm{O}$ índice de respostas foi bastante satisfatório, abrangendo 92\% dos alunos, $78 \%$ dos pais e $78 \%$ dos professores, num total de 2.597 questionários (1.092 alunos, 1.045 pais e 260 professores).

16 Apresentamos os sete motivos, entre os 15 propostos, que obtiveram maiores percentuais de indicação entre os pais. 
- Diálogo da escola com os pais aparece com grande ênfase principalmente na escola pública, 92\%, mas também com percentual expressivo na rede privada, $76 \%$, reforçando o reconhecimento da importância da parceria entre as duas principais instituições responsáveis pela educação das novas gerações;

- Escola bem falada é um aspecto muito valorizado tanto pelos pais do setor público, 89\%, quanto pelos pais do setor privado, 75\%. A expressão bem falada, mais coloquial, expressaria a importância das redes informais e de sociabilidade próxima na formação da opinião dos pais, principalmente entre aqueles da rede pública. Essa suposição é reforçada pela forte referência à indicação das fontes de informação sobre a escola (Quadro 11), onde é predominantemente referida a experiência vivenciada pela rede social formada por amigos e familiares com a escolarização das novas gerações.

Dois outros motivos aparecem como muito importantes apenas em uma das redes (Quadro 10b):

\section{Quadro 10b - Motivos de escolha de escola}

\begin{tabular}{|l|r|r|}
\hline \multicolumn{1}{|c|}{ Motivo de escolha da escola } & Rede Privada & Rede Pública \\
\hline O espaço e as instalações da escola são muito bons & $78 \%$ & $60 \%$ \\
\hline A escola exige muito do aluno & $73 \%$ & $84 \%$ \\
\hline
\end{tabular}

Fonte: Elaboração das autoras.

- Espaço e instalaçóes da escola aparece com maior ênfase entre os pais da rede privada, 78\%, do que da pública, o que pode ser explicado em função de uma certa padronização que caracteriza as construções das escolas da rede pública;

- Por sua vez, escola que exige muito do aluno é enfatizado principalmente no caso da rede pública, $84 \%$, reforçando a ideia de que uma escola exigente amplia as possibilidades de acesso para os alunos que contam com menor capital cultural da família.

Cabe destacar ainda que os $40 \%$ das respostas dos pais das escolas públicas no que se refere à importância da localização da escola perto de casa pouco contrastam com os $34 \%$ dos pais da rede privada. As eventuais dificuldades de ordem financeira ou prática, ou seja, a preocupação com despesas de transporte e a impossibilidade de contratar terceiros para se responsabilizar pelo deslocamento dos filhos parecem ficar em segundo plano e não limitam as escolhas quando se trata de encontrar uma boa escola para os filhos.

Para os pais usuários das escolas privadas, nossos dados indicam que a aprovação no vestibular pesa $22 \%$ mais do que para os pais que optaram pelo setor público (esse item apresentou a maior variação entre as redes privada e pública). Para famílias de níveis de escolarização superior, a entrada na universidade é destino necessário dos filhos e a experiência tem apontado para consultas cada vez mais frequentes aos resultados do ENEM e rankings de vestibulares, desde o momento da 
escolha da primeira escola para os filhos, ainda na educação infantil. Já no caso dos pais do setor público, normalmente o horizonte tende a se ampliar à medida que os filhos vão desenvolvendo uma trajetória escolar mais longa, alcançando patamares superiores aos que os próprios pais conseguiram chegar. Além disso, a ampliação da oferta do ensino superior e uma série de políticas de inclusão nesse nível de ensino para alunos provenientes das escolas públicas (entre elas o PROUNI) contribuem para a diminuição da tensão em relação ao futuro escolar dos filhos, o que explicaria uma perspectiva mais pragmática, de curto e médio prazo, no que tange à escolarização dos filhos.

Apesar dessas diferenças, cabe lembrar que a amostra de nossa pesquisa contempla escolas de qualidade em ambos os setores. Os dados que apresentamos anteriormente indicam níveis de escolaridade dos pais de estudantes das escolas municipais bem superiores à média da população brasileira, mesmo que ainda sejam inferiores aos dos pais de alunos das escolas privadas investigados pelo survey. Eles representam, portanto, setores da nova classe média - amplamente debatida não só no mundo acadêmico, mas também pela mídia -, com maior possibilidade de acesso à informação, com melhores níveis de renda familiar e com maiores expectativas a respeito da escola e da educação. ${ }^{17}$ Um forte indicador desse novo perfil da classe média ascendente encontra-se nos percentuais muito próximos - 93\% e $98 \%$ - de pais dos setores público e privado que indicaram sua preocupação com ensino de boa qualidade, na ocasião da escolha da escola.

Sabemos que a escolha da escola é fortemente influenciada pelo capital informacional do qual as famílias podem lançar mão para subsidiar suas decisões. Possibilidades limitadas de acessar informações sobre as escolas que integram a rede de ensino parecem ser compensadas pelas famílias populares com o apoio de parentes, amigos e vizinhos que fornecem indicações preciosas para otimizar as escolhas, conforme detalhado no Quadro 11. Cabe destacar também a presença da mídia como fonte de informação no caso das famílias das escolas particulares, praticamente não assinalada pelos pais dos alunos das escolas públicas.

Quadro 11 - Fonte de informações sobre a escola

\begin{tabular}{|l|r|r|}
\hline $\begin{array}{c}\text { Onde você conseguiu informações para escolher a escola } \\
\text { do seu filho? (Marque as DUAS PRINCIPAIS fontes de } \\
\text { informação) }\end{array}$ & Rede Privada & Rede Pública \\
\hline Mídia & $19 \%$ & $5 \%$ \\
\hline Escolas & $25 \%$ & $15 \%$ \\
\hline Rede de profissionais da escola & $13 \%$ & $22 \%$ \\
\hline Rede social (parentes e amigos) & $43 \%$ & $58 \%$ \\
\hline
\end{tabular}

Fonte: Elaboração das autoras.

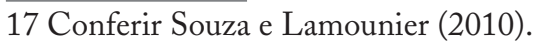




\section{O empenho das famílias na escolarização dos filhos}

No que se refere à participação na vida escolar dos filhos, ${ }^{18}$ é importante destacar a semelhança de atitudes de ambos os grupos de pais em relação às exigências escolares. Percebemos que os níveis menores de escolaridade dos pais das escolas públicas não parecem ser impeditivos de uma atitude empenhada para o bom rendimento escolar dos filhos.

\section{Quadro 12 - Ações realizadas pelos pais na vida escolar dos filhos}

\begin{tabular}{|l|r|r|}
\hline \multicolumn{1}{|c|}{ Participação dos pais na vida escolar dos filhos } & Rede Privada & Rede Pública \\
\hline Analiso as notas do boletim & $99 \%$ & $97 \%$ \\
\hline Mantenho-me informado & $96 \%$ & $88 \%$ \\
\hline Faço questão que ele tire boas notas & $92 \%$ & $98 \%$ \\
\hline Apoio as decisões da escola & $77 \%$ & $82 \%$ \\
\hline Verifico as tarefas escolares & $54 \%$ & $70 \%$ \\
\hline
\end{tabular}

Fonte: Elaboração das autoras.

Os altos percentuais que aparecem no Quadro 12 em relação aos itens analiso as notas do boletim, mantenho-me informado, faço questão que tire boas notas e apoio as decisóes da escola praticamente se equivalem nas duas redes. As respostas dos pais das escolas públicas indicam que a menor escolaridade em relação aos pais da rede privada não os impede de adotar uma atitude de atenção permanente no acompanhamento do trabalho escolar dos filhos.

A verificação das tarefas escolares, que representa uma forma de acompanhamento mais intenso da escolarização dos filhos, no caso dos pais das escolas públicas, se insere na convicção crescente da importância da escolaridade para o futuro dos filhos (Souza; Lamournier, 2010). Em contrapartida, a menor intensidade da atenção dos pais mais escolarizados já foi tema de reflexão de uma investigação sobre a escolarização dos filhos das elites acadêmicas. ${ }^{19}$

A pergunta sobre a frequência com que os filhos estudam em casa nos oferece um interessante quadro das repercussões do envolvimento das famílias com a escolarização dos filhos. No que toca aos estudantes das escolas privadas, o habitus escolar - entendido como disposições duráveis para o estudo - provavelmente foi desenvolvido sob a égide da herança familiar, sendo portanto o resultado da repercussão do patrimônio de diferentes capitais da família ${ }^{20}$ - ambiente familiar e social com amplo acesso às pautas culturais valorizadas pelo meio escolar - na

18 Analisamos cinco indicadores que apareceram entre os nove pesquisados.

19 Mais informação em: Brandão e Lelis (2003).

20 Capital cultural, linguístico, econômico etc. 
constituição das disposições que favorecem o desempenho escolar. No caso dos estudantes das escolas públicas, além da ampliação cultural derivada da ascensão de setores das antigas camadas populares à nova classe média brasileira, o próprio impulso resultante dessa mobilidade recente parece repercutir num investimento mais consciente dos pais. Estes passam a proporcionar aos filhos atividades e bens de consumo antes restritos aos setores que lhes eram superiores, tais como ensino de qualidade, acesso à internet, ampliação das fontes de informação e outros, favorecendo o desenvolvimento de disposições para o estudo.

Quadro 13 - Frequência do estudo em casa

\begin{tabular}{|l|r|r|}
\hline \multicolumn{1}{|c|}{ Com que frequência seu filho estuda em casa? } & Rede Privada & Rede Pública \\
\hline Todos os dias & $48 \%$ & $29 \%$ \\
\hline Duas a três vezes por semana & $25 \%$ & $30 \%$ \\
\hline Uma vez por semana & $3 \%$ & $6 \%$ \\
\hline Só em véspera de prova & $23 \%$ & $30 \%$ \\
\hline Nunca & - & $3 \%$ \\
\hline Não sei & $1 \%$ & $2 \%$ \\
\hline
\end{tabular}

Fonte: Elaboração das autoras.

Quase 50\% dos alunos das escolas privadas estudam diariamente em casa, como pode ser observado no Quadro 13, segundo a percepção das famílias, o que certamente corresponde ao esperado de filhos cujos pais procuraram as melhores e mais exigentes escolas do setor privado do município do Rio de Janeiro. No caso dos alunos das escolas públicas, cerca de 30\% realizam estudos diários em casa, segundo a percepção dos pais. São jovens oriundos de famílias que apenas recentemente tiveram acesso a níveis de escolarização média, ${ }^{21}$ e que, apesar da ausência de um elevado capital cultural familiar, evidenciam disposições para o estudo. Outros 30\% do mesmo grupo estudam de duas a três vezes por semana; esses percentuais são indicadores eloquentes, a nosso ver, do acompanhamento e empenho das famílias dos alunos das escolas públicas de nossa amostra, em prol de uma escolaridade de melhor qualidade para os seus filhos.

O movimento das famílias de ambas as redes em direção à valorização dos estudos fica claro também quando os alunos apontam que a escola e os estudos aparecem com frequência como tema de conversa entre pais e filhos (Quadro 14).

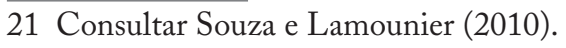


Quadro 14-Temas de conversas entre pais e filhos

\begin{tabular}{|l|r|r|}
\hline \multicolumn{1}{|c|}{ Temas de conversa } & Rede Privada & Rede Pública \\
\hline Sobre seus estudos & $91 \%$ & $91 \%$ \\
\hline Sobre sua escola & $93 \%$ & $93 \%$ \\
\hline
\end{tabular}

Fonte: Elaboração das autoras.

\section{A relação dos pais com os profissionais da escola}

Família e escola compartilham a responsabilidade pela educação das crianças, porém nem sempre se percebem como parceiras nessa relação. Enfrentando dificuldades, provenientes não só de lógicas socializadoras diferentes que caracterizam as famílias dessas instituições, mas também da relação desigual que se estabelece, principalmente no caso das famílias populares que não detêm o capital cultural que a escola solicita, família e escola precisam superar o desafio da construção de uma relação baseada no diálogo. $\mathrm{Na}$ pesquisa realizada, encontramos, entretanto, uma percepção bastante semelhante entre os pais da rede privada e da rede pública $-63 \%$ e $60 \%$ respectivamente, conforme indicado no Quadro 15 - que ilustra o reconhecimento de uma escuta permanente e uma abertura para o diálogo por parte da escola caracterizando-se como um diferencial das melhores escolas.

Quadro 15 - A escola ouve a família

\begin{tabular}{|l|r|r|}
\hline \multicolumn{1}{|c|}{ Quando você solicita entrevista ou apresenta sugestões: } & Rede Privada & Rede Pública \\
\hline A escola sempre ouve & $63 \%$ & $60 \%$ \\
\hline A escola às vezes ouve & $33 \%$ & $32 \%$ \\
\hline A escola nunca ouve & $4 \%$ & $8 \%$ \\
\hline
\end{tabular}

Fonte: Elaboração das autoras.

Baseados nesse indício de diálogo verificamos, como detalhado nos Quadros 16a e 16b, como a parceria se torna presente nas situações em que o aluno enfrenta problemas de aprendizagem, levando-nos a acreditar que na rede pública há um maior direcionamento da família para acionar a escola, tanto na figura do professor, quanto da coordenação. Ao contrário da rede privada, onde cerca de 50\% dos pais declara que nunca ou raramente busca o apoio da escola. Na perspectiva da escola, quando é ela a identificar as dificuldades dos alunos, os professores indicam que muitas vezes ou sempre buscam o apoio das famílias em ambos os grupos (Quadro 17). 
Quadro 16 a - Quando o aluno apresenta desempenho ruim, a família?

\begin{tabular}{|l|r|r|}
\hline \multicolumn{1}{|c|}{ Fala com o professor } & Rede Privada & Rede Pública \\
\hline Nunca ou raramente & $49 \%$ & $32 \%$ \\
\hline Às vezes & $28 \%$ & $25 \%$ \\
\hline Quase sempre ou sempre & $23 \%$ & $43 \%$ \\
\hline
\end{tabular}

Fonte: Elaboração das autoras.

Quadro 16 b - Quando o aluno apresenta desempenho ruim, a família?

\begin{tabular}{|l|r|r|}
\hline \multicolumn{1}{|c|}{ Fala com a coordenadora da escola } & Rede Privada & Rede Pública \\
\hline Nunca ou raramente & $51 \%$ & $36 \%$ \\
\hline Às vezes & $23 \%$ & $27 \%$ \\
\hline Quase sempre ou sempre & $26 \%$ & $37 \%$ \\
\hline
\end{tabular}

Fonte: Elaboração das autoras.

Quadro 17 - Quando o aluno apresenta desempenho fraco, a escola?

\begin{tabular}{|l|r|r|}
\hline \multicolumn{1}{|c|}{ Busca apoio da família } & Rede Privada & Rede Pública \\
\hline Nunca ou raramente & $15 \%$ & $11 \%$ \\
\hline Algumas vezes & $38 \%$ & $35 \%$ \\
\hline Muitas vezes ou sempre & $47 \%$ & $54 \%$ \\
\hline
\end{tabular}

Fonte: Elaboração das autoras.

\section{O ALUNO COMO AGENTE NA CONSTITUIÇÃO DO HABITUS}

O conjunto de percepções e atividades dos alunos ajuda-nos a dimensionar o processo de aquisição dos habitus escolares. Como agente ativo do processo de escolarização, o aluno é o principal elemento de intermediação entre a esfera escolar e familiar.

Aspectos muito importantes na constituição dos habitus escolares podem ser analisados por meio dos nossos dados sobre a trajetória escolar do aluno focalizando a frequência à educação infantil - amplamente caracterizada como elemento diferenciador no desempenho dos estudantes. ${ }^{22} \mathrm{~A}$ permanência na mesma escola ao longo de todo o ensino fundamental pode ser uma referência importante sobre a

22 Duru-Bellat (2005) desenvolveu um estudo sobre a trajetória dos estudantes na França, caracterizando-a e articulando-a ao desempenho no final do ciclo de escolarização fundamental (collèges e licées) e as condições de entrada no nível superior. A pesquisadora aponta que as diferentes trajetórias estudantis, destacando as gêneses dessas trajetórias, elaboram uma espécie de estrutura de desigualdade, com desempenhos insatisfatórios que convergem em uma lógica de acumulação construída ao longo da escolarização. 
constituição do habitus, na medida em que indica o trabalho realizado na construção do perfil de aluno desejado pela instituição. Quanto maior a inserção do aluno no ambiente de escolarização, maior também será seu tempo de exposição às rotinas, aos valores e regras institucionais, favorecendo a aquisição de hábitos de estudo e posturas que contribuem para alcançar o desempenho esperado pela escola.

A socialização precoce fora da família, através do ingresso na educação infantil, mesmo que cursada em diferentes escolas, concorre para a facilitação da constituição desse habitus. Tal etapa de ensino, cada vez mais vivenciada em instituiçôes quase totais, onde se realizam não só atividades cognitivas para o desenvolvimento de um inconsciente acadêmico, mas para o incentivo e a organização de hábitos de alimentação, higiene e comportamento de maneira geral, representam condição privilegiada para o futuro desempenho escolar (Ciccourel, 2007, p. 171).

Quadro 18 - Série de ingresso na escola

\begin{tabular}{|l|r|r|}
\hline \multicolumn{1}{|c|}{ Em que série você ingressou nesta escola? } & Rede Privada & Rede Pública \\
\hline Educação Infantil & $14 \%$ & $12 \%$ \\
\hline $1^{\circ}$ ano & $20 \%$ & $11 \%$ \\
\hline $2^{\circ}$ ano & $21 \%$ & $7 \%$ \\
\hline $3^{\circ}$ ano & $5 \%$ & $2 \%$ \\
\hline $4^{\circ}$ ano & $4 \%$ & $5 \%$ \\
\hline $5^{\circ}$ ano & $14 \%$ & $13 \%$ \\
\hline $6^{\circ}$ ano & $7 \%$ & $30 \%$ \\
\hline $7^{\circ}$ ano & $5 \%$ & $6 \%$ \\
\hline $8^{\circ}$ ano & $6 \%$ & $6 \%$ \\
\hline $9^{\circ}$ ano & & $6 \%$ \\
\hline
\end{tabular}

Fonte: Elaboração das autoras.

O Quadro 18 mostra que na rede privada $41 \%$ dos alunos ingressaram na escola no início do ensino fundamental ( $1^{\circ}$ e $2^{\circ}$ anos), enquanto na rede pública o menor ingresso nas séries iniciais pode estar associado à própria organização da rede municipal, onde parte das escolas oferece apenas o primeiro segmento desse nível de ensino. No $6^{\circ}$ ano, aparece na rede pública um aumento significativo de ingresso de novos alunos, que pode ser considerado como representativo da procura dos pais por uma escola de qualidade para a finalização dessa etapa. ${ }^{23}$ Contudo, percebemos que os valores são decrescentes conforme se avança para as últimas séries, indicando a provável presença de um contingente de alunos já ambientado à escola no $9^{\circ}$ ano.

Além da trajetória, o bom clima escolar experimentado nas escolas exerce grande influência na manutenção dos habitus (Quadro 19a e 19b). Podemos identificar, com

23 Lembramos da concorrência por vagas nas boas escolas de nível médio, com particular interesse pelas instituições da rede federal no Rio de Janeiro. 
pequenas diferenças entre as escolas investigadas (e com resultados sutilmente mais favoráveis na rede pública), que os alunos reconhecem a escola como um ambiente agradável, com destaque para o reconhecimento da escola como local de fazer amizades.

\section{Quadro 19a-Senso de pertencimento}

\begin{tabular}{|l|r|r|}
\hline Minha escola é um lugar onde eu faço amigos facilmente & Rede Privada & Rede Pública \\
\hline Discordo & $12 \%$ & $9 \%$ \\
\hline Concordo & $88 \%$ & $91 \%$ \\
\hline
\end{tabular}

Fonte: Elaboração das autoras.

Quadro 19b - Senso de pertencimento

\begin{tabular}{|l|r|r|}
\hline \multicolumn{1}{|c|}{ Minha escola é um lugar onde eu me sinto entediado } & Rede Privada & Rede Pública \\
\hline Concordo & $26 \%$ & $18 \%$ \\
\hline Discordo & $74 \%$ & $82 \%$ \\
\hline
\end{tabular}

Fonte: Elaboração das autoras.

A boa relação com os agentes escolares (Quadros 20a e 20b) em ambas as redes também reforça a indicação do bom clima. Além de favorecer a cordialidade entre os agentes, o clima pode funcionar como indício de adesão ao trabalho realizado pela escola, representando a postura favorável do aluno à prática dos professores e às atividades de manutenção do habitus escolar.

Quadros 20a - Relação com os agentes escolares

\begin{tabular}{|l|r|r|}
\hline Como você classifica o relacionamento com seus colegas? & Rede Privada & Rede Pública \\
\hline Ruim & $1 \%$ & $2 \%$ \\
\hline Razoável & $4 \%$ & $6 \%$ \\
\hline Bom & $95 \%$ & $92 \%$ \\
\hline
\end{tabular}

Fonte: Elaboração das autoras.

Quadro 20b - Relação com os agentes escolares

\begin{tabular}{|l|r|r|}
\hline $\begin{array}{c}\text { Como você classifica o relacionamento } \\
\text { com seus professores? }\end{array}$ & Rede Privada & Rede Pública \\
\hline Ruim & $1 \%$ & $1 \%$ \\
\hline Razoável & $12 \%$ & $20 \%$ \\
\hline Bom & $87 \%$ & $79 \%$ \\
\hline
\end{tabular}

Fonte: Elaboração das autoras.

Além de classificarem positivamente as regras de convivência da escola (Quadros 21a, 21b), a maioria dos alunos nas duas redes afirma respeitar essas regras na maior parte das aulas. Esses valores, particularmente na rede pública, apontam para uma perspectiva contrária aos estudos que identificam baixa adesão dos alunos às regras disciplinares, o que por vezes se manifesta na imagem de violência na escola. 
Quadro 21a - Clima escolar e acadêmico

\begin{tabular}{|l|r|r|}
\hline \multicolumn{1}{c|}{$\begin{array}{c}\text { Como você classifica as regras } \\
\text { de convivência na sua escola? }\end{array}$} & Rede Privada & Rede Pública \\
\hline Ruim & $6 \%$ & $6 \%$ \\
\hline Razoável & $19 \%$ & $19 \%$ \\
\hline Bom & $76 \%$ & $75 \%$ \\
\hline
\end{tabular}

Fonte: Elaboração das autoras.

Quadro 21b - Clima escolar e acadêmico

\begin{tabular}{|l|r|r|}
\hline \multicolumn{1}{|c|}{$\begin{array}{c}\text { Os alunos respeitam as regras } \\
\text { de convivência da escola? }\end{array}$} & Rede Privada & Rede Pública \\
\hline Nunca ou raramente & $2 \%$ & $7 \%$ \\
\hline Em algumas aulas & $20 \%$ & $31 \%$ \\
\hline Na maioria ou em todas as aulas & $78 \%$ & $63 \%$ \\
\hline
\end{tabular}

Fonte: Elaboração das autoras.

Outro elemento importante a ser considerado na investigação do habitus escolar é o comportamento do aluno em sala de aula na medida em que suas ações distinguem um saber gerir acadêmico. ${ }^{24}$ Tais comportamentos socioculturais se manifestam como ações para além das atividades propriamente cognitivas, em atitudes necessárias à resolução de problemas, linguagem e manifestação de emoções, entre outros elementos valorizados pelo professor e percebidos como necessários à aprendizagem.

Nos itens sobre o clima acadêmico (Quadros 22a, 22b), identificamos uma série de comportamentos favoráveis ao bom desempenho do aluno. Além da postura atenta na sala de aula, $74 \%$ na rede privada e $67 \%$ na rede pública - comportamento que primariamente se explicita na aquisição do habitus favorável ao desempenho -, identifica-se também alto nível de autonomia entre os alunos, que afirmam procurar o professor quando precisam de ajuda.

24 Expressão utilizada por Duru-Bellat (2005) para designar as práticas dos estudantes franceses na administração da própria trajetória escolar, dentro do panorama de um sistema escolar que se complexifica na França. Lançamos mão da expressão, acrescentando o adjetivo acadêmico para caracterizar o comportamento em sala de aula, fazendo menção ao senso do jogo, conceituado por Bourdieu. 
Quadro 22a-Clima acadêmico

\begin{tabular}{|l|r|r|}
\hline \multicolumn{1}{|c|}{$\begin{array}{c}\text { Os alunos procuram o professor } \\
\text { quando precisam de ajuda? }\end{array}$} & Rede Privada & Rede Pública \\
\hline Nunca & $2 \%$ & $5 \%$ \\
\hline Em algumas aulas & $27 \%$ & $29 \%$ \\
\hline Na maioria ou em todas as aulas & $71 \%$ & $66 \%$ \\
\hline
\end{tabular}

Fonte: Elaboração das autoras.

Quadro 22b - Clima acadêmico

\begin{tabular}{|l|r|r|}
\hline \multicolumn{1}{|c|}{ Os alunos prestam atenção ao que o professor fala? } & Rede Privada & Rede Pública \\
\hline Nunca & - & $2 \%$ \\
\hline Em algumas aulas & $26 \%$ & $31 \%$ \\
\hline Na maioria ou em todas as aulas & $74 \%$ & $67 \%$ \\
\hline
\end{tabular}

Fonte: Elaboração das autoras.

Aqui também se observa uma proximidade entre os valores, com uma diferença de apenas $5 \%$ entre as redes. Atenção e autonomia - elementos propícios ao bom clima acadêmico e à aprendizagem - favorecem, ao mesmo tempo, o trabalho docente, a manutenção do tempo de aula (aspecto importante para o cumprimento dos programas), o rendimento e o desempenho da turma, além da relação professor-aluno. ${ }^{25}$

\section{À GUISA DE CONCLUSÃO}

A exploração dos dados que apresentamos, derivados de parte das respostas obtidas nos questionários dos pais e dos alunos, nos ofereceu um material bastante expressivo das ações das famílias que, em conjunção com aquelas adotadas pelas escolas, se complementam no objetivo de promover educação e ensino de qualidade.

Identificamos sinais de novas configurações no acompanhamento do ensino pelas famílias, um possível reflexo de alterações nos extratos médios da sociedade brasileira e no perfil das classes populares. Um dos achados mais instigantes desta pesquisa refere-se à atuação empenhada dos pais dos alunos da rede pública no acompanhamento da escolarização de seus filhos. Outro aspecto interessante da mudança nessas relações se expressa na possibilidade da escolha da escola, devido à não setorização obrigatória por meio da moradia. Essas famílias buscam escolas públicas que se destacam pelo ensino e pelo engajamento de seus agentes escolares. Nesse contexto, não encontramos indícios de culpabilização das famílias, mas um comprometimento consciente da ação da escola na construção e manutenção do

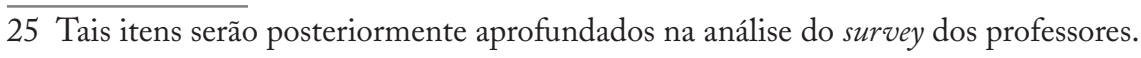


habitus escolar. Esse tipo de aliança entre famílias e escolas pode ser considerado como marca distintiva dessas instituições.

Em meio a diferenças marcantes na estrutura e no funcionamento das escolas que pesquisamos, identificamos perfis semelhantes na gestão pedagógica e na construção e manutenção de um habitus escolar favorável ao bom desempenho dos alunos, com repercussão no clima escolar e acadêmico. Além da possibilidade de superação do senso comum sobre o ensino público municipal no Rio de Janeiro, pudemos caracterizar algumas peculiaridades que perpassam condições sociais distintas de acesso a bens culturais e à escolarização e que concorrem para a construção de um ensino de qualidade.

Essas, entre outras questões, devem continuar a ser exploradas com recortes que focalizarão as semelhanças e singularidades das práticas familiares e estudantis e o cruzamento de rotinas e valores escolares e familiares no processo de construção do habitus escolar nos sistemas de ensino público e privado.

A construção de uma perspectiva de análise, possível por meio do conceito de habitus proposto por Bourdieu, nos auxiliou a identificar e caracterizar os principais investimentos da escola e da família, levando-nos a construir perfis da experiência estudantil em escolas públicas e privadas e ampliando, ao mesmo tempo, nossa percepção sobre a qualidade nessas escolas, cujo sentido tem sido principalmente respaldado pelos sistemas de avaliação oficiais. Algumas similitudes encontradas giram em torno de aspectos como a onipresença do diretor em diferentes momentos do cotidiano escolar, o comprometimento dos agentes escolares e os indícios de uma experiência escolar positiva entre os alunos. Em semelhante medida, os "tipos ideais weberianos" nos orientaram na caracterização das escolas e na observação de suas culturas escolares e identidades institucionais.

Muito do que temos percebido desde o início da pesquisa indica que os processos de produção de qualidade do ensino resultam de uma relação bastante complexa de demandas, inquietações e esforços, tanto da instituição familiar como da escolar, aspectos esses geradores quer de tensões, quer de compromissos mútuos, e que aparentemente se desdobram no desenvolvimento de habitus escolares que conduzem essas escolas ao ápice dos rankings divulgados sobre as melhores escolas públicas e privadas do município do Rio de Janeiro.

\section{REFERÊNCIAS}

Bernstein, Basil. Social class, language, and socialization. In: Karabel, Jerome; Halsey, Albert H. (Ed.). Power and ideology in education. New York: Oxford University Press, 1977. 
Bourdieu, Pierre. La distinction: critique social du jugement. Paris: Les Éditions Minuit, 1979.

BRAga VIANA, Maria J. Longevidade escolar em famílias populares: algumas condições de possibilidades. Goiânia: Editora da UCG, 2007.

BRANDÃo, Zaia; LeLIS, Isabel. Elites acadêmicas e escolarização dos filhos. Educação E Sociedade, Campinas: CEDES (Centro de Estudos Educação e Sociedade), v. 83, p. 509-526, 2003.

Ciccourel, Aaron V. As manifestações institucionais e cotidianas do habitus. Tradução de Sergio Miceli. Tempo Social, São Paulo: USP, v. 19, n. 1, p. 169-188, 2007.

Duru-Bellat, Marie. Amplitude e aspectos peculiares das desigualdades sociais na escola francesa. Educação e Pesquisa, São Paulo: USP, v. 31, n. 1, p. 13-30, jan./abr. 2005. Foreuin, Jean C. Sociologia da educação: dez anos de pesquisa. Petrópolis: Vozes, 1995. Freire, Paulo. Educação como prática da liberdade. 19. ed. Rio de Janeiro: Paz e Terra, 1989.

LAHIRE, Bernard. Sucesso escolar nos meios populares: as razões do improvável. São Paulo: Ática, 1997.

Paes de Carvalho, Cynthia. Entre as promessas da escola e os desafios da reprodução social: famílias de camadas médias do ensino fundamental à universidade. 2004. Tese (Doutorado em Educação) - PUC-Rio, Rio de Janeiro.

; Lacerda, Patrícia. Contratos de sucesso escolar: problematizando interpretações sobre a relação família-escola. In: Reunião AnUAL DA ANPOCs, 31., 2007, Caxambu, Minas Gerais. Anais. Caxambu, 2007. ST29.

PoRTEs, Ecio. Trajetórias e estratégias escolares do universitário das camadas populares. 1993. Dissertação (Mestrado em Educação) - Universidade Federal de Minas Gerais (UFMG), Minas Gerais.

Souza E Silva, Jailson. Por que uns e não outros? Caminhada de jovens pobres para a universidade. Rio de Janeiro: 7Letras, 2003.

Souza, Amaury de; LAmounier, Bolivar. A classe média brasileira: ambições, valores e projetos de sociedade. Rio de Janeiro: Elsiever; Brasília: CNI, 2010.

\section{SOBRE AS AUTORAS}

Zaia Brandẽo é doutora em educação pela Pontifícia Universidade Católica do Rio de Janeiro (PUC-Rio). Professora titular da mesma instituição. E-mail: zaiapucrio@gmail.com 
Maria Luiza Canedo é doutoranda em educação pela Pontifícia Universidade Católica do Rio de Janeiro (PUC-Rio). E-mail: luiza.canedo@uol.com.br

Alice Xavier é doutoranda em educação pela Pontifícia Universidade Católica do Rio de Janeiro (PUC-Rio).

E-mail: alicepx@yahoo.com.br

Recebido em agosto de 2011 Aprovado em novembro de 2011 


\section{ZAIA BRANDÃO, MARIA LUIZA CANEDO E ALICE XAVIER}

\section{Construção solidária do habitus escolar: resultados de uma investigação nos setores público e privado}

Nosso objetivo no presente trabalho foi ampliar a compreensão do processo de desenvolvimento e manutenção do habitus escolar que favorece o desempenho dos estudantes de ensino fundamental. Analisamos parte das respostas fornecidas por pais e alunos bem como as observações de campo obtidas durante a aplicação de um survey em um conjunto formado por dez escolas públicas municipais e privadas da cidade do Rio de Janeiro. As escolas incluídas na amostra pesquisada foram escolhidas com base nos resultados obtidos pelos alunos na Prova Brasil e no ENEM. Apresentamos os resultados da análise cruzada das rotinas e esforços familiares com as práticas institucionais que apontam para o reforço de disposições favoráveis ao sucesso escolar. Encontramos entre as famílias de camadas populares indícios de empenho relativamente maior no acompanhamento e apoio aos estudos, do que nas famílias dos alunos de nível sociocultural mais elevado. Este resultado levou-nos a procurar caracterizar as experiências estudantis e as diferentes formas de apoio familiar que respondem às demandas escolares. Encontramos ainda estilos de gestão institucional que, articulados a estilos de lidar com a escolaridade dos filhos por parte das famílias, indicam a presença de estratégias combinadas de produção de habitus escolares, oferecendo um panorama instigante para o debate sobre o efeito-escola em estabelecimentos de prestígio.

Palavras-chave: relação família-escola; habitus escolar; escolas de qualidade. 


\section{Solidary construction of students habitus: results of a survey developed in public and private schools}

This paper aims to enlarge the knowledge about the development and maintenance of the students habitus that reinforce the good performance of elementary school students. We analysed some parents and students answers as well as some notes that we got during a survey developed in ten of the best public and private schools in Rio de Janeiro. The schools included in this research sample were choosen based on the students results in Prova Brasil and ENEM. This paper shows some results of a crossed analysis between the routines and family efforts and institutional practices that pointed to the reinforcement of the student habitus that supports their good performances in those schools. We find among popular families traces of a relatively stronger parent's engagement to accompany and support their children studies than among the families with higher social and cultural level. This result drove us to pursuit students experience and characteristics of family support that reinforce the student habitus as an answer of school requests. We also find different management styles articulated with family styles to deal with children scholarity indicating the presence of combined strategies to produce the student habitus, offering an instigate overview about family and school relationship in the production of schools quality.

Keywords: family-school relationship; student habitus; schools quality.

\section{Construcción solidária del habitus escolar: resultados de una investigación en los setores público y privado}

Nuestro objetivo en el presente trabajo fue ampliar la comprensión del proceso de desarrollo y manutención del habitus escolar que favorece los ingresos de los estudiantes del enseño fundamental. Analizamos parte de las respuestas fornecidas por los padres y alumnos asi como las observaciones de campo obtenidas en la aplicación de uno survey en un grupo de diez escuelas públicas municipes y privadas del Rio de Janeiro/Brazil. El resultado de los alumnos en la Prueba Brasil y en el ENEM fueran la basis para sí incluir las escuelas en la muestra investigada. Presentamos los resultados del análisis cruzada de las rutinas y esfuerzos familiares con las prácticas institucionales que muestran el esfuerzo de disposiciones favorables para el éxito académico. Nosotros encontramos entre las familias de clase popular evidencias de un esfuerzo relativamente mayor en el acompañamiento y apoyo a los estudios, que en las familias de alumnos de nivel socio-cultural más elevado. Este resultado nos bice buscar caracterizar las experiencias estudiantiles y las diferentes formas de apoyo familiar que responden a las demandas académicas. También hemos encontrado estilos de gestión institucional que, articulados a estilos de tratar con la escolaridad de los bijos por parte de las familias, indican la presencia estratégica combinada de producción de habitus académicos, ofreciendo uno panorama excitante para el debate del efecto-escuela en estabelecimientos de prestigió.

Palabras clave: relación familia-escuela; habitus académicos; escuelas de calidad. 